\title{
Unintended right-to-left shunt after Fontan operation: Consequence of unligated vertical vein in a child with total anomalous pulmonary venous drainage, single ventricle, and heterotaxy
}

\author{
David Mishaly, MD, Julius Hegesh, MD, Mira Frand, MD, Aram Smolinsky, MD, and Gabriel Amir, MD, Tel Aviv, Israel
}

$\mathrm{L}$ igation of the vertical vein (VV) during the correction of total anomalous pulmonary venous drainage (TAPVD) is controversial. ${ }^{1-3}$ Most surgeons usually ligate or divide the VV, but others support a potential benefit in leaving it patent to serve as a possible vent for relatively hypoplastic, noncompliant left heart chambers. ${ }^{1,2}$ The fate of an unligated VV late after correction of a TAPVD is unclear; both no flow $^{1,4}$ and patent veins with considerable left-to-right shunting ${ }^{3,5}$ have been reported. We report a rare case of persistent cyanosis after a Fontan procedure in a patient with a VV left open after correction of infracardiac TAPVD and emphasize the importance of $\mathrm{VV}$ ligation in this special setting of single ventricle and TAPVD.

\section{Clinical Summary}

A 3.5-year-old girl was seen with persistent cyanosis after completion of the Fontan operation. She had a diagnosis from birth of infracardiac TAPVD, a double-outlet right ventricle, transposition of the great arteries, mitral atresia, and heterotaxy with right isomerism and asplenia. Correction of total anomalous venous connection without ligation of the infracardiac VV and pulmonary artery banding was performed. When she was 1 year old, she underwent a bidirectional Glenn shunt and division of the pulmonary artery and had saturation levels in the $80 \%$ range after that operation. At the age of 3.5 years, she underwent completion of the nonfenestrated Fontan operation with an 18 -mm polytetrafluoroethylene extracardiac conduit.* She was more profoundly cyanotic after that operation than she had been before it. There was no respiratory explanation for the low saturation levels. In a search for a residual systemic vein draining into the atrium, she underwent catheterization; however, injection into the inferior vena cava and both arms demonstrated no residual right-to-left shunt causing the persistent cyanosis.

* Gore-Tex conduit; registered trade name of W. L. Gore \& Associates, Inc, Flagstaff, Ariz.

From the Department of Pediatric Cardiology and Cardiac Surgery, The Chaim Sheba Medical Center, Tel Hashomer, Israel, affiliated to the Sackler Faculty of Medicine, Tel Aviv University, Tel Aviv, Israel.

Received for publication June 10, 2002; accepted for publication July 1, 2002.

Address for reprints: David Mishaly, MD, Department of Congenital and Pediatric Cardiac Surgery, Haim Sheba Medical Center, Tel Hashomer 52621, Israel (E-mail:

J Thorac Cardiovasc Surg 2003;125:421-3

Copyright $\odot 2003$ by The American Association for Thoracic Surgery $0022-5223 / 2003 \$ 30.00+0$

doi: $10.1067 / \mathrm{mtc} .2003 .144$
Spiral contrast computed tomography revealed a patent infracardiac VV (Figure 1). This was confirmed by ultrasonography, which corroborated the diagnosis and showed reversal of flow from the inferior vena cava through the hepatic veins to the hepatic sinusoids and portal veins through the patent VV into the common atria, creating a significant right-to-left shunt.

VV ligation was performed through a right thoracotomy (Figure 2) and provided immediate improvement in oxygen saturation. Recovery was uneventful, and the patient was discharged home with an oxygen saturation level of $97 \%$.

\section{Comments}

VV ligation during TAPVD repair is controversial, as is the fate of the unligated VV. Failing to demonstrate flow in an unligated vein in long-term follow-up, some authors have concluded that cessation of flow occurs spontaneously. ${ }^{1,4}$ Others have found patent veins with persistent left-to-right shunting. ${ }^{3,6}$ Most surgeons ligate the ascending or descending $\mathrm{VV}$ to prevent potential adverse sequelae of left-to-right shunting ${ }^{1}$; others leave the VV unligated to serve as a "pop off valve" to the left heart chambers, which are believed to be hypoplastic and noncompliant ${ }^{7}$ and to cause low cardiac output after the operation. Hepatic ischemia after infradiaphragmatic VV ligation draining to the portal vein has convinced several surgeons to selectively leave the VV open. ${ }^{6}$ To determine whether VV ligation is essential to successful surgical repair, Cope and colleagues ${ }^{1}$ reviewed their experience with 23 infants who underwent correction of TAPVD and concluded that VV ligation is not routinely necessary and may even be undesirable in patients with pulmonary vein obstruction. Furthermore, Caspi and associates $^{2}$ reviewed 34 infants after operation and concluded that maintaining the VV patent in selected patients with infracardiac TAPVD contributes to a favorable postoperative outcome. Others, however, have described significant left-to-right shunts as being serious consequences of an unligated VV. 3,5

Operative mortality is high in patients with single ventricle and TAPVD, and long-term outcome is poor. ${ }^{8}$ Leaving the VV patent in these high-risk patients at the time of TAPVD repair is logical, because it probably contributes to a smoother postoperative course. Furthermore, left-to-right shunting has no meaning in this setting, because the pulmonary veins and the inferior vena cava drain into the same atrial chamber during the first two stages of singleventricle repair.

In our case the flow reversed through the hepatic veins, hepatic parenchyma, and the portal vein (without disruption of liver functions) through the VV into the common atrium and caused a significant right-to-left shunting, as in a large Fontan fenestration, because systemic venous pressure is higher than pulmonary venous pressure at the time of the completion of the Fontan operation. Ligation of the infradiaphragmatic VV resulted in immediate 

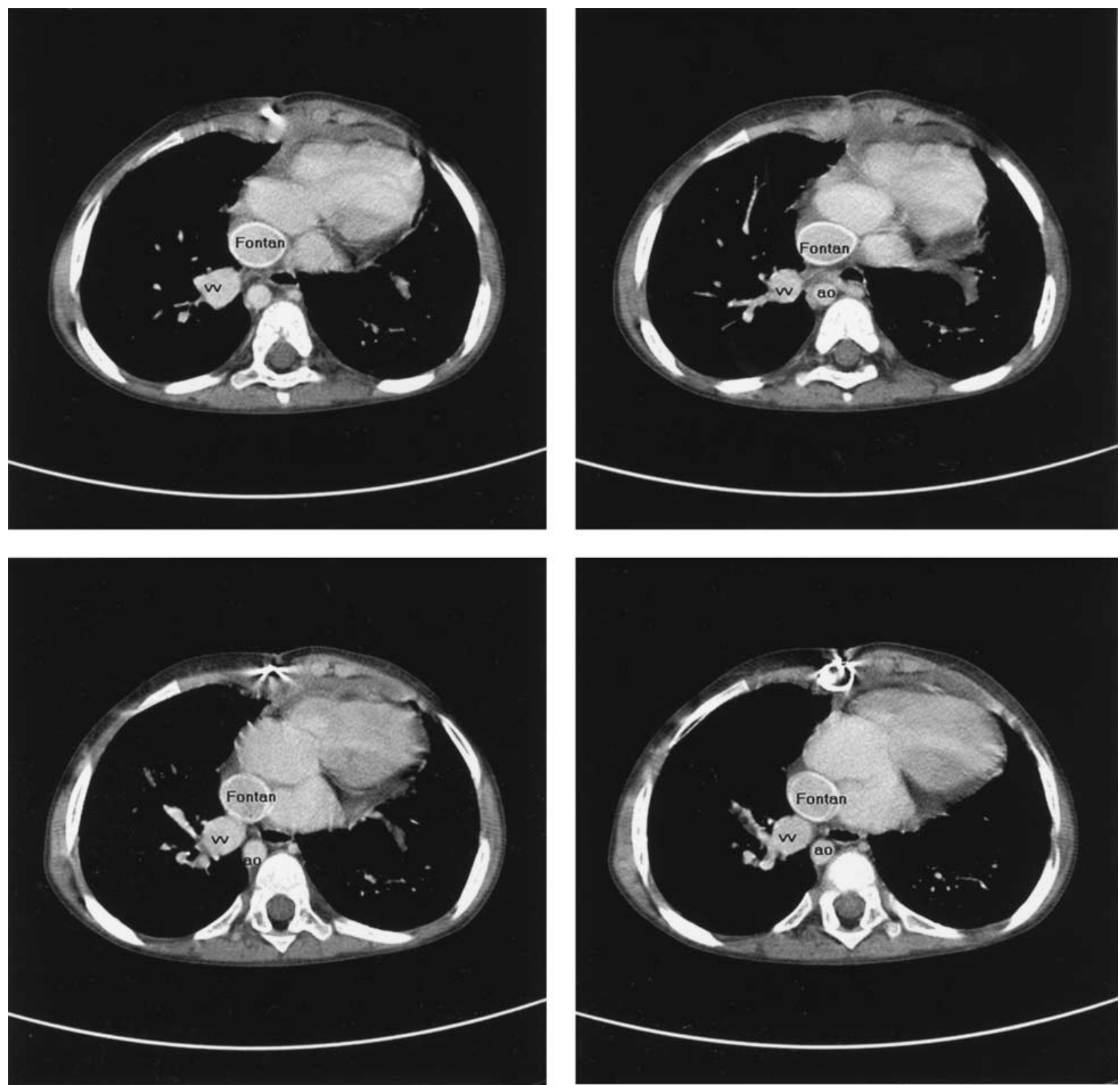

Figure 1. Spiral contrast computed tomography showing patent VV coming off portal vein and draining to right lower pulmonary vein. ao, Aorta.

improvement. In light of the our described experience, we support the advocates of ligation of the VV, at least when the Fontan operation is completed, to prevent late cyanosis and shunting.

We thank Esther Eshkol for editorial assistance.

\section{References}

1. Cope JT, Banks BS, McDaniel NL, Shokey KS, Nolan SP, Kron IL. Is vertical vein ligation necessary in repair of total anomalous pulmonary venous connection? Ann Thorac Surg. 1997;64:23-9.

2. Caspi J, Pettitt TW, Fontenot EE, Stopa AR, Heck HA, Munfakh NA, et al. The beneficial hemodynamic effects of selective patent vertical vein following repair of obstructed total anomalous pulmonary venous drainage in infants. Eur J Cardiothorac Surg. 2001;20:830-4.

3. Shah MJ, Shah SJ, Shankargowda S, Krishnan U, Cherian KM. L $\rightarrow$ R shunt: a serious consequence of TAPVC repair without ligation of vertical vein. Ann Thorac Surg. 2000;70:971-3.

4. Jegier W Charrette E, Dobell AR. Infradiaphragmatic anomalous pulmonary venous drainage: normal hemodynamics following operation in infancy. Circulation. 1967;35:396-400.

5. Kumar RN, Dharmapuram AK, Rao IM, Gopalakrishnan VC, Pillai VR, Nazer YA, et al. The fate of the unligated vertical vein after surgical correction of total anomalous pulmonary venous connection in early infancy. $J$ Thorac Cardiovasc Surg. 2001;122: $615-7$. 

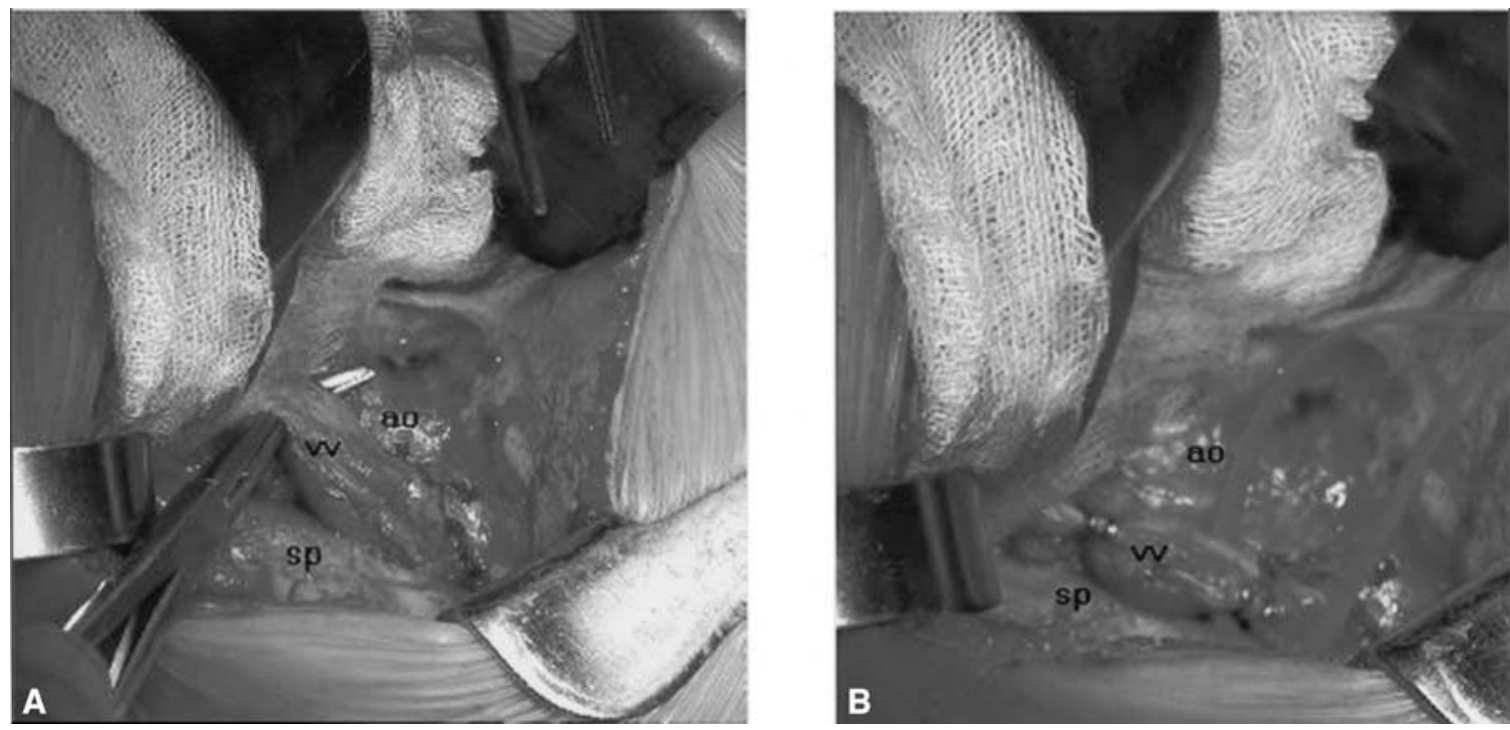

Figure 2. A, Operative view showing wide open VV parallel to aorta (ao) and spine (sp). B, VV is seen to be ligated with double clips.

6. Appelbaum A, Kirklin JW, Pacifico AD, Bargeron LM Jr. The surgical treatment of total anomalous pulmonary venous connection. Isr J Med Sci. 1975;11:89-96.

7. Mathew R, Thilenius OG, Replogle RL, Arcilla RA. Cardiac function in total anomalous pulmonary venous return before and after surgery.
Circulation. 1977;55:361-70

8. Gaynor JW, Collins MH, Rychick J, Gaugan JP, Spray TL. Long term outcome of infants with single ventricle and total anomalous pulmonary venous connection. J Thorac Cardiovasc Surg. 1999; 117:506-13.

\title{
Mitral annular and left ventricular outflow tract enlargement with autologous tissue: Extended application of the Ross-Konno procedure
}

\author{
José M. Caffarena, MD, PhD, ${ }^{a, b}$ Miguel Rovirosa, MD, ${ }^{b}$ and Jose M. Gòmez-Ullate, MD, ${ }^{a}$ Barcelona, Spain
}

$\mathrm{T}$ unnel-type subaortic stenosis with aortic valve involvement combined with mitral stenosis and annular hypoplasia, frequently seen with Shone anomaly or related conditions, may have a severe presentation in infancy, with aortic valvulotomy and mitral valve replacement being nec-

From the Pediatric Cardiac Surgery Department, Children's Hospital La $\mathrm{Fe},{ }^{\mathrm{a}}$ Valencia, and Children's Hospital Sant Joan de Deu, ${ }^{\mathrm{b}}$ Barcelona, Spain.

Received for publication July 12, 2002; accepted for publication July 18, 2002.

Address for reprints: José M. Caffarena, MD, PhD, Pediatric Cardiac Surgery Department, Hospital Infantil La Fe, C/ Avda de Campanar s/n, 46009 Valencia, Spain (E-mail: josecaffarena@telefonica.net).

J Thorac Cardiovasc Surg 2003;125:423-5

Copyright $\odot 2003$ by The American Association for Thoracic Surgery

$0022-5223 / 2003 \$ 30.00+0$

doi: $10.1067 / \mathrm{mtc} .2003 .202$ essary at an early age. ${ }^{1}$ These patients subsequently may have severe gradients across the mitral prosthesis because of body growth, along with frequent complex aortic obstructions that are aggravated by the protrusion of the mitral prosthesis into the left ventricular outflow tract.

Faced with the seeming inevitability of performing a double mitral-aortic valve replacement, we developed an alternative technique that enlarges the mitral annulus, allowing the accommodation of a prosthesis of a greater size and at the same time resolving the complex aortic obstruction. The objective is to minimize the use of prosthetic material and to use autologous tissue in these growing children.

\section{Method}

We use deep hypothermic cardiopulmonary bypass. After aortic crossclamping, blood cardioplegic solution is administered through the aortic root. The retrograde route is used for dose maintenance. The aorta is sectioned along the commissural plane, and the aortic valve is resected, with extraction of coronary arteries 